\title{
Carbon Nanotube and Graphene Aerogels - The World's 3D Lightest Materials for Environment Applications: A Review
}

\author{
Phan Ngoc Hong ${ }_{3,2}$, *, Dang Nhat Minh ${ }^{1,3}$, Nguyen Van Hung ${ }^{1}$, Phan Ngoc Minh ${ }^{1,2}$, \\ Phan Hong Khoi ${ }^{3, *}$ \\ ${ }^{1}$ Institute of Materials Science, Vietnam Academy of Science and Technology, Hanoi, Vietnam \\ ${ }^{2}$ Graduate University of Science and Technology, Vietnam Academy of Science and Technology, Hanoi, Vietnam \\ ${ }^{3}$ Center for High Technology Development, Vietnam Academy of Science and Technology, Hanoi, Vietnam
}

\section{Email address:}

hongpn@ims.vast.ac.vn (P. N. Hong),phkhoi@htd.vast.vn (P. H. Khoi)

${ }^{*}$ Corresponding author

\section{To cite this article:}

Phan Ngoc Hong, Dang Nhat Minh, Nguyen Van Hung, Phan Ngoc Minh, Phan Hong Khoi. Carbon Nanotube and Graphene Aerogels - The World's 3D Lightest Materials for Environment Applications: A Review. International Journal of Materials Science and Applications. Vol. 6, No. 6, 2017, pp. 277-283. doi: 10.11648/j.ijmsa.20170606.12

Received: August 25, 2017; Accepted: September 13, 2017; Published: October 29, 2017

\begin{abstract}
Carbon Nanotube and Graphene Aerogels (CNTAs \& GAs)- the world's lightest 3D materials (GA isseven times lighter than air - a cubic meter weighs just 160 grams) attracted widespread attention due to their excellent mechanical compressible properties, high temperature and thermal stability, recyclable and highly efficient organic pollutants adsorption capability (GA can absorb up to 900 times its own weight in oil and do so quickly, with one gram of Aerogel able to absorb up to 68.8 grams of organics per second). In this review, we present briefly recent progress in synthesis methods for fabrication of 3D CNTAs andGAs and their emerging applications in the field of environmental protection such as removingoil, organic pollutants, arsenic ions and other toxic metalsfrom water. Furthermore, to assist advanced research for practical applications of these 3D materials, the technical challenges are discussed, and future research directions are proposed.
\end{abstract}

Keywords: Carbon Nanotube Aerogels, Graphene Aerogels, 3D Materials, Environment Protection, Applications

\section{Introduction}

Aerogels are a diverse class of ultralow density and extremely porous solids with properties unlike anything else. These materials are synthesized from a gel, in which the liquid component of the gel has been replaced with a gas by different techniques. The first aerogel was invented by Samuel Stephens Kistler in 1931, which were made from silica and later work involved aerogels based on alumina, chromia and tin dioxide [1]. Silica aerogel is the most common type of aerogel and the most extensively studied. Due to its translucent nature and the way light scatters in the material, silica aerogel is also called "frozen smoke", "solid smoke", "solid air", or "blue smoke". The lowest-density of the recorded silica aerogel is $1,900 \mathrm{~g} / \mathrm{m}^{3}$ with the remaining $97 \%$ of the volume composed of air in extremely small nanopores, extremely low thermal conductivity, from 0.03 $\mathrm{W} / \mathrm{m} . \mathrm{K}$ in atmospheric pressure down to $0.004 \mathrm{~W} / \mathrm{m} . \mathrm{K}$ in modest vacuum. Itsoptical transmission is very high and the refractive index is of $\sim 1.05$. Until 2011, the silica aerogel held 15 entries in Guinness World Records for material properties, including best insulator and lowest-density solid [2]. Owing to these extraordinary properties, silica aerogel has been intensively studied and successfully used in various application fields, such as thermal and acoustic insulation in building construction, modern-day products manufacturing like shock-absorbers in cars, cradling aircraft flight data recorders, protecting fragile laptop computer hard drives and super light-weight and warm ski jackets and so on.

Up-to-now several types of aerogels such as metal oxide aerogels, organic/polymer aerogels, carbon aerogels, CNTs/graphene aerogels have been studied and developed. Figure 1 shows the types of aerogel and their evolutiontimeline. 


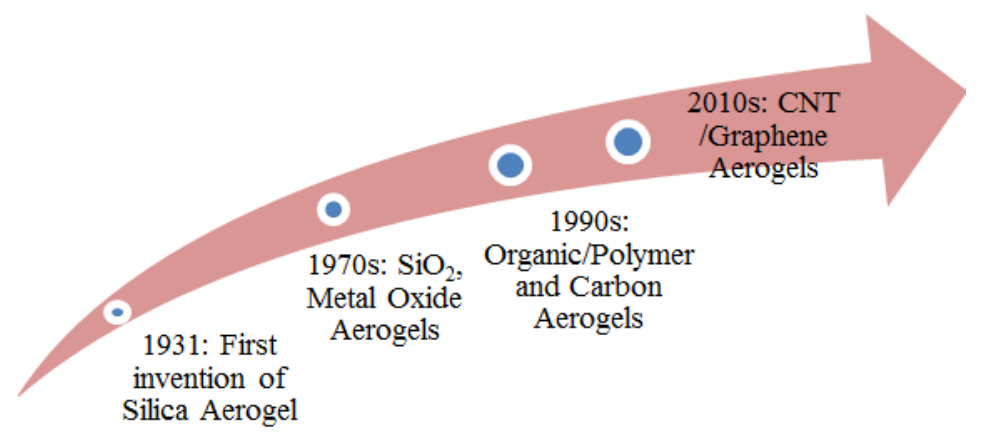

Figure 1. Types andevolution timeline of the aerogels [3].

Among the types of aerogel denoted in Figure 1, CNT and graphene aerogels have attracted considerable attentions for investigation because of their prominent properties: welldefined and controlled pore structure, large surface area, high electrical conductivity, heat-\& fire-resistance and thermal/mechanical stability, which make them innovative and promising materials for various applications.

Herein, we review recent research achievements on three-dimensional (3D) CNT and graphene aerogels for purposes of environment protection applications including removal of oils, organic pollutants andheavy toxic metal ions from contaminated water andadsorption of toxic gases in air.

\section{Methods for Synthesizing Aerogels}

\subsection{GeneralMethod for Synthesizing Aerogels}

Aerogels have been fabricated using traditional organic sol-gel chemistry. A procedure of aerogels preparation in general, carbon nanotube (CNT) and graphene aerogels, in particular, is shown in the Figure 2.

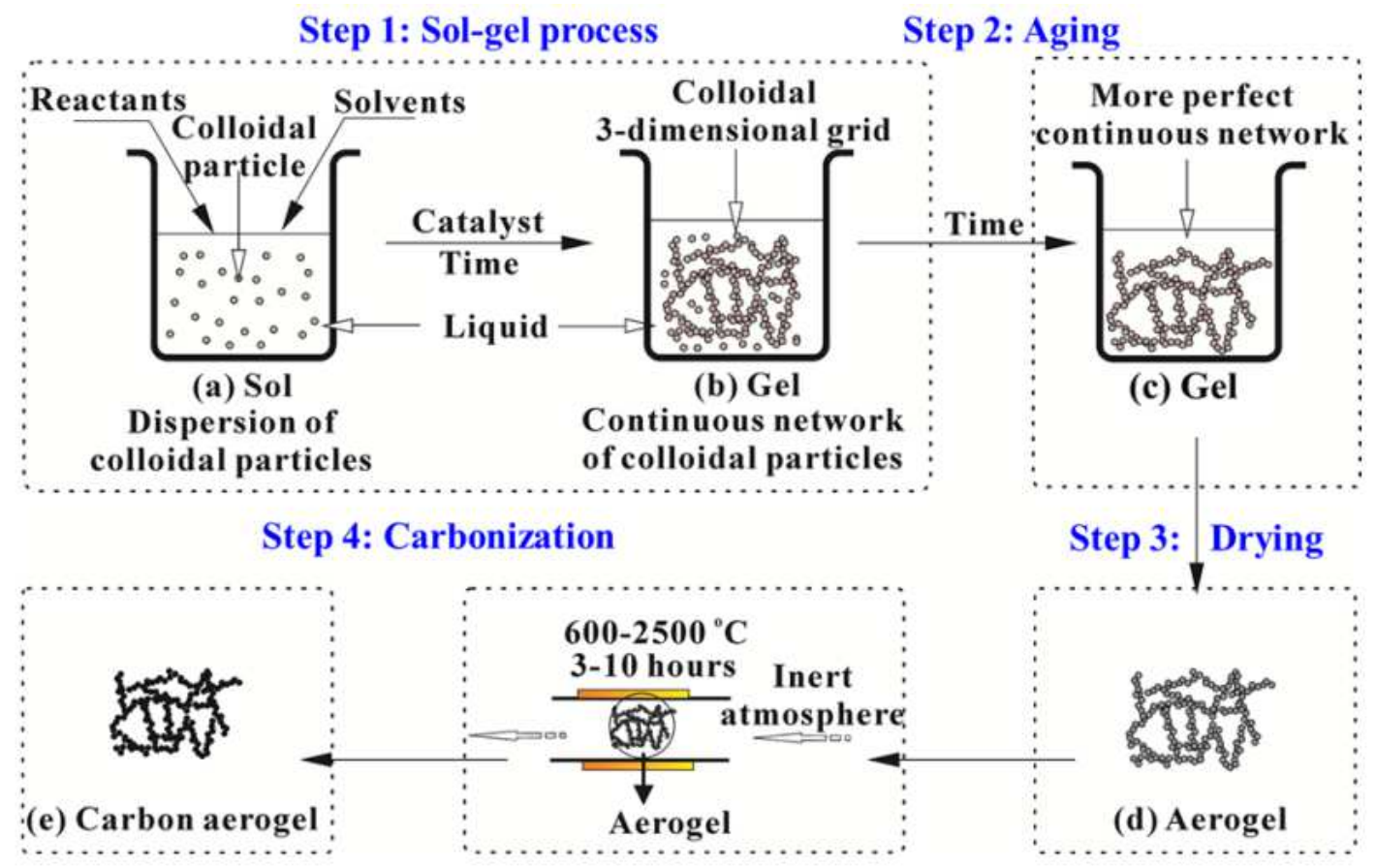

Figure 2. A general procedure for aerogel preparation [3].

The procedure consists of 04 main steps as follow: (1) Step 1: Sol-gels preparation; (2) Step 2. Aging of the sol-gels; (3) Step 3: Drying which may be performed using one of the following techniques: (i) Direct evaporation from liquid phase to gas phase causes collapse to the gel network due to the effect of surface tension, (ii) Supercritical drying (CPD) process: the temperature and pressure of liquid are raised above its critical point to form a supercritical fluid. By slowly releasing the pressure, the hydrogels are dried to aerogels with well-preserved networks, and (iii) Freeze drying is a common method to create aerogels. During this process, the samples are fast frozen and then placed in a vacuum under raised temperature to allow the ice to sublimate; (4) Step 4. Carbonization: The aerogels are carbonized at high temperature in an inert atmosphere for several hours to form carbon-based aerogels [3].

To produce CNT and graphene aerogels the following materials are usually used (1) Nanomaterials: CNTs (MW or 
SW), graphene sheets, graphene flacks, graphene oxides (GO), reduced graphen oxide (RGO), metal/metal oxide nanoparticles and organic/polymers (for fabrication hybrid nanocomposite aerogels); (2) Solutions and catalysts: ID water, various kind of chemical compounds. There are several techniques for fabrication of CNT \& graphene aerogels. However, in framework of the review, in the next section we willbriefly describe only a room temperature freeze gelation (RTFG) technique for fabrication of multiwall carbon nanotube (MWCNT) Polyvinyl alcohol(PVA) hybrid aerogel since this method is rather simple and promised to be able to produce inexpensive aerogels in large scale. The same technique can be used to produce hybrid graphene aerogels.

\subsection{Room Temperature Freeze Gelation (RTFG) Techniquefor Synthesizing MWCNT-PVAHybrid Aerogels}

Room-temperature freeze gelation (RTFG) was originally developed by Halloran and co-workers for the manufacture of ceramics [4] and has been recently used by Lizeng Zuo and his co-authors to fabricate polymer/carbon-based hybrid aerogels[3]. This processing route is similar to conventional aqueous freeze gelation (or freeze casting) but with the water replaced by an organic solvent selected to have a melting temperature greater than room temperature and a high vapor pressure. The material to be processed is mixed and dispersed in the solvent above its melting point, typically in the temperature range $50-120^{\circ} \mathrm{C}$ and cooled to form a solid at room temperature. The solvent is selected to have a high vapor pressure above the solid at room temperature and thus rapidly sublimes at room temperature under ambient atmospheric conditions, leaving a porous solid of the original material.

In our study we used phenol $\left(\mathrm{C}_{6} \mathrm{H}_{6} \mathrm{O}\right)$ melting at low temperature $40.5^{\circ} \mathrm{C}$ with the addition of polyvinyl alcohol (PVA) in solution to increase the strength of the resulting aerogel. Thesol-gelsolidification and phenol evaporation can be performed at room temperature. A schematic of how the RTFG process is used for MWCNT aerogel preparation is illustrated in Figure 3 [5].

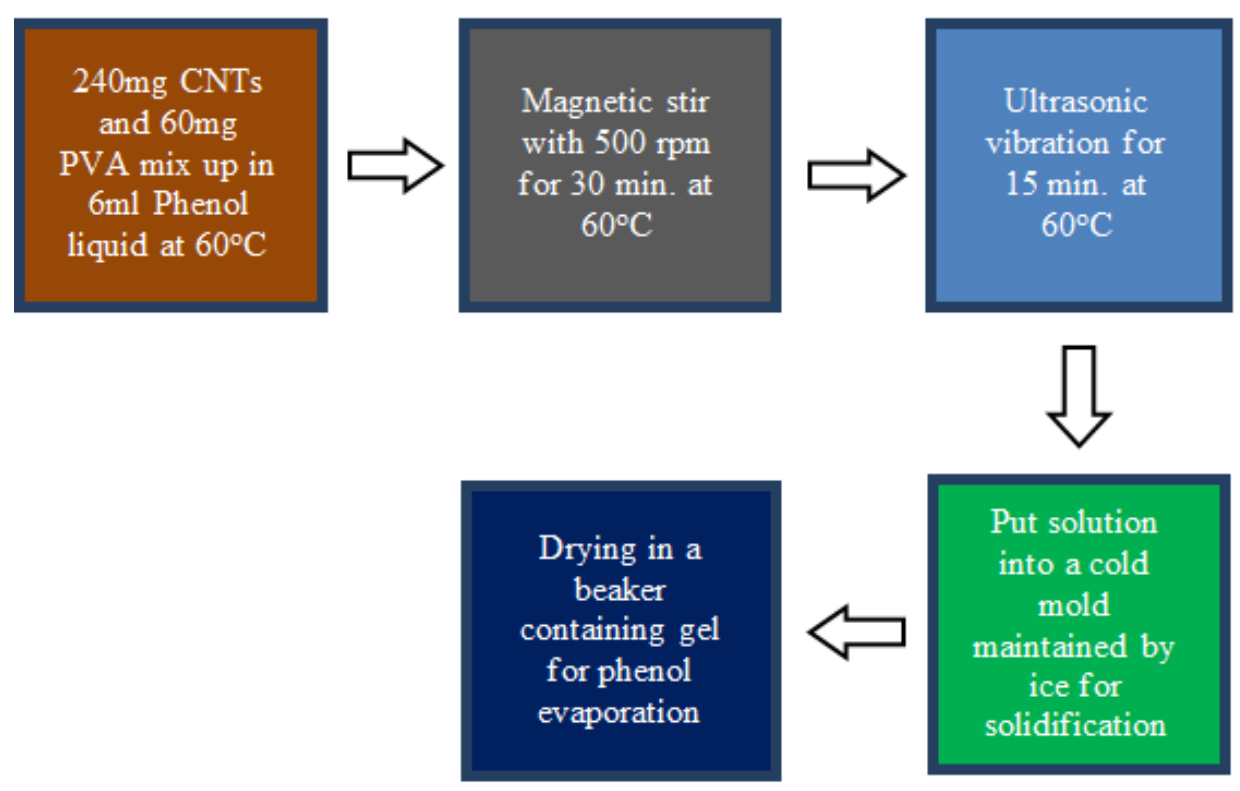

Figure 3. Schematic of the room-temperature freeze gelation (RTFG) process [5].

Briefly, the preparation procedure of MWCNT/PVA aerogel is following: MWCNTs are dispersed to the required concentration in an appropriate solvent at $60^{\circ} \mathrm{C}$, using magnetic stir with $500 \mathrm{rpm}$ for $30 \mathrm{~min}$. and ultrasonic vibration for $15 \mathrm{~min}$. to form a stable dispersion. This dispersion is then used with an appropriate forming method, e.g., molding and cooled in ice to promote solidification. The resulting waxy solid contains a uniform suspension of MWCNTs. The solvent sublimes at room temperature leaving a porousMWCNT aerogel. Theoptical image and microstructure of RTFG MWCNT aerogel obtained is shown in Figure 4.
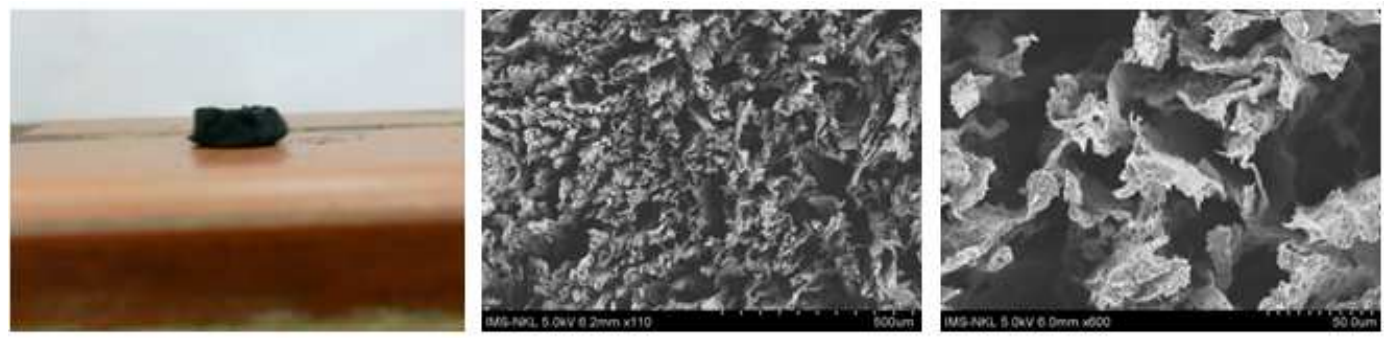

Figure 4. An optical image (Left) and microstructures (Right) of RTFG MWCNT aerogel [5]. 
With the same procedure, Yue Lin, et al. have recently successfully produced the RTFG aerogel using mixtures of graphene flakes and MWCNT, mixtures of rGO and MWCNT with the addition of polymers in solution to increase the strength of the resulting aerogel [6].

\section{Specific Properties of CNT and GrapheneAerogels}

CNT and graphene aerogels are solid, rigid, and dry materials that do not resemble a gel in their physical properties. The name comes from the fact that they are made from gels. They exhibit extraordinary properties that do not have any other materials.

a).They are the world's lightest materials ever known:The density of GAs synthesized by a chemical reduction method and dried with supercritical $\mathrm{CO}_{2}$ is 14.1- 52.4 $\mathrm{mg} / \mathrm{cm}^{3}$ [7], and according to the report of Chinese researchers at Zhejiang University, the lowest-density of the recorded graphene aerogel is 0.16 milligrams $/ 1 \mathrm{~cm}^{3}$, seven times lighter than air (air density is $\left.-11,8 \mathrm{mg} / 1 \mathrm{~cm}^{3}\right)[8,9]$

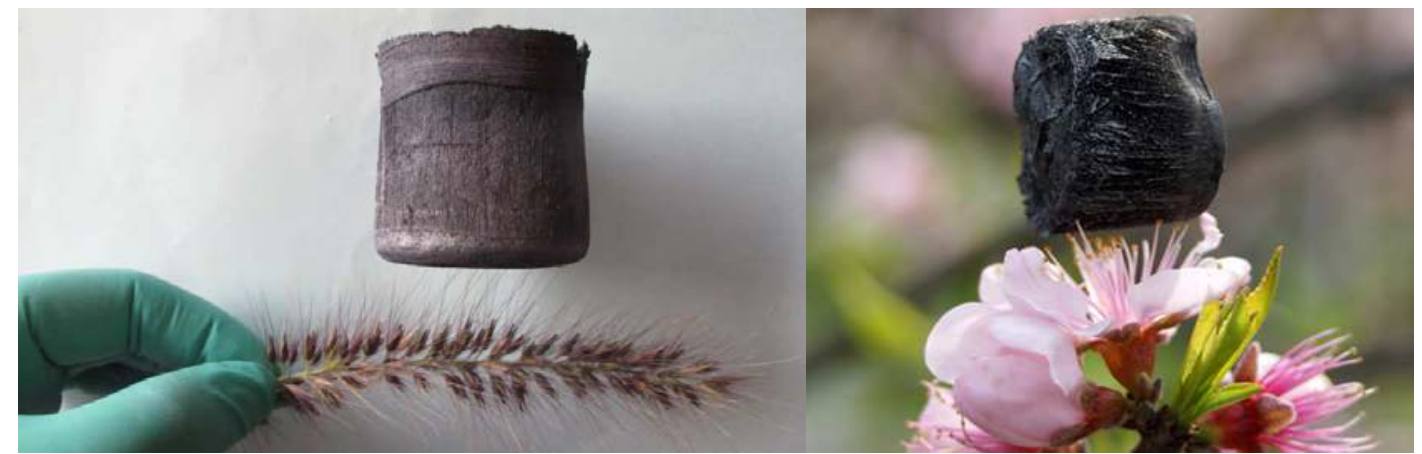

Figure 5. The graphene aerogel is so light that a cube inch of the stuff can be balanced on a blade of grass(Left) and sitting on top of a plant's leaves (Right) [10].

b). They are the most porous solid network that contains air pockets, with the air pockets taking up majority of space within the material, therefore aerogel is a material that is $\sim 98.2 \%$ air;

c). Their surface area is very high ranging between 400 $1,000 \mathrm{~m}^{2} / \mathrm{g}$ [2].

d). They exhibit extremely low thermal conductivity because they are composed almost entirely of gas, which are very poor heat conductors. At room temperaturethe lowest thermal conductivity of CNT AerogelK $=0.01 \div 0.1$ (W/m.K) [2] and of graphene aerogel $\mathrm{K}=4.7 \times 10^{-3} \div 5.9 \times 10^{-3}(\mathrm{~W} / \mathrm{m} . \mathrm{K})$ [8], much lower than pristine CNT and GrapheneK $=2,000$ $\div 5,300$ (W/m.K) (Silica aerogel is especially good because silica is also a poor conductor of heat; CNT and graphene aerogels would be less effective, but on the other side, they exhibit excellent heat and fire resistant properties).

e). They are mechanically strong and extremely elastic, bouncing back after being compressed. The graphene aerogel can recover completely after more than $90 \%$ compression [5]. Recently, Cheng et al. reported that $75.0 \mathrm{mg}$ graphene aerogel cylinder could support a $2 \mathrm{~kg}$ counterpoise, at least 26000 times their own weight as can be seen in the figure 6 [11].
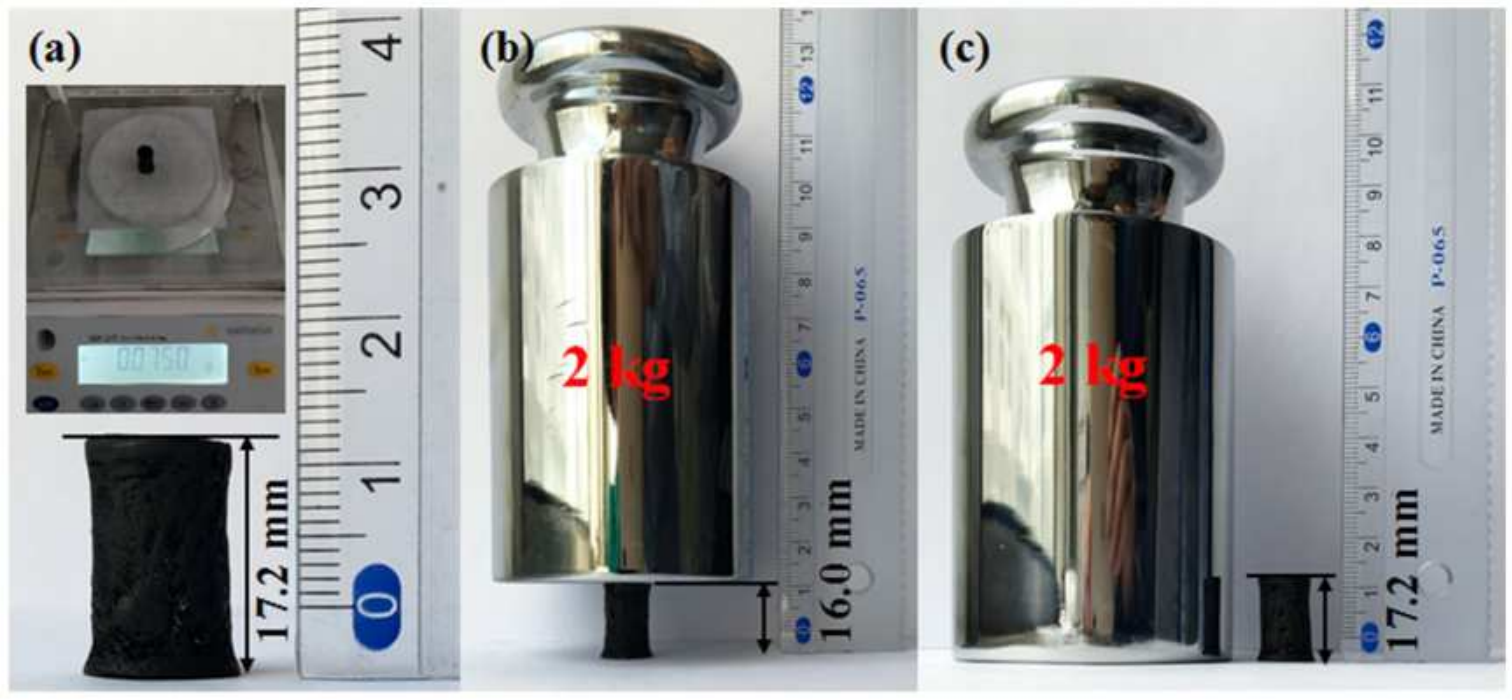

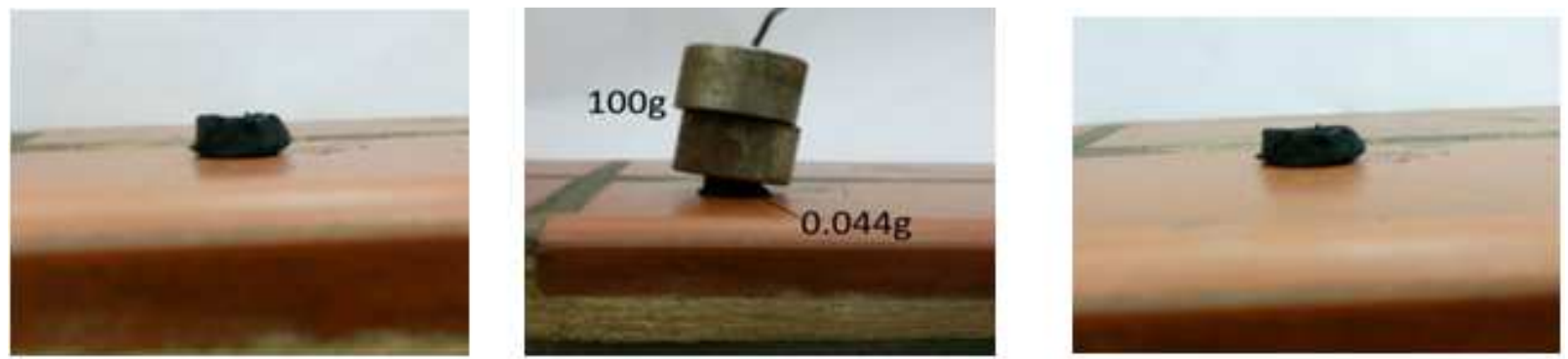

Figure 6. CNT \&Graphene Aerogels are extremely elastic, bouncing back after being compressed [5, 11].

f). They exhibit excellent properties of hydrophobicity and adsorption of oils, organic pollutants, heavy metalions, toxic gases.

Hence, it is no surprise that CNT and Graphene aerogels provide some of the most amazing benefits that may see them being used soon in most industries and environment applications. In the framework of this review, we present abrief description on some attracted applications of CNT and graphene aerogels only for environment protection.

\section{Applications for Environment Protection}

Environmental pollution especially oils, organic pollutants, heavy metalions, toxic gases in waterand air, caused by industry and agricultural activities, severely affects ecological balance and human health, and has received extensive attention worldwide. It is why research for finding new materials and methods for effectively removing these pollutants in water and airis necessary and urgent.

Currently, many adsorbents and materials have been

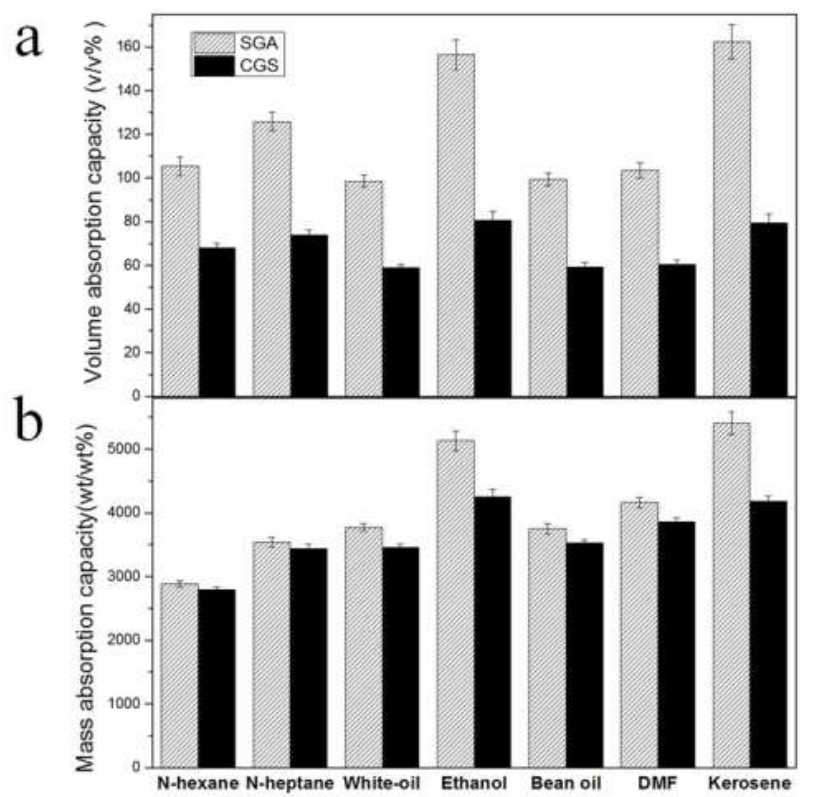

researched and developed. Among them, nanomaterials, especially, carbon nanotube and graphenein general, and their aerogels in particular, have been considered as the most perspective materials for various environment protection applications.

\subsection{Removal of Oils and Organic Pollutants from Water}

The hydrophobicity of MWCNT and graphene aerogels makes them good candidates for removing oils and organic pollutants from water. Lizeng Zuo et al. reported that the uptake capacity of a thermally treated MWCNThybrid aerogel is up to about 37 times of its weight for various lubricating oils, and to about 23 times for vegetable oils [3]. Recently, Luo et al. successfully synthesized superhydrophobic spongy graphene aerogels which is able to adsorb up to 29-54 times its own mass with the slightly lower density than other aerogel composites $\left(24 \pm 2 \mathrm{mgcm}^{-3}\right)$ (figure 7 and 8a-b) [12]. An ultralight GA with density $<3 \mathrm{mg} \mathrm{cm}^{-3}$ reported by Zhang et $a l$. shows very high $\mathrm{n}$-hexane absorption capacity $(\mathrm{Q}=226)$ (figure 8c) [13].

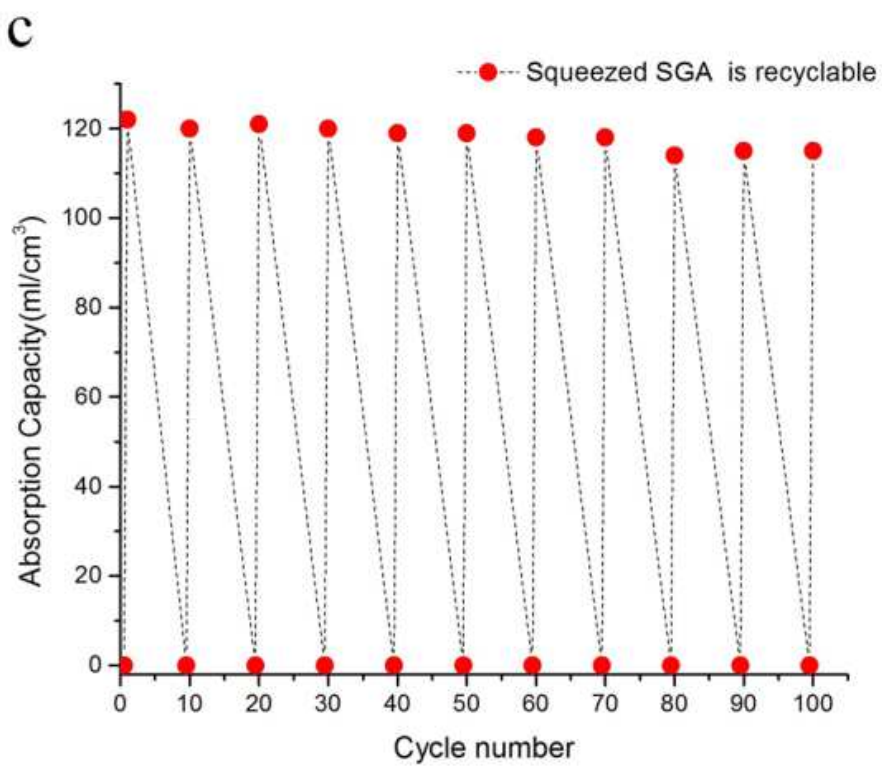

Figure 7. The absorption capacities of different organic liquids on a (a) mass basis and (b) volume basis, (c) The high absorption recyclability of GA with $n$ heptane[12]. 

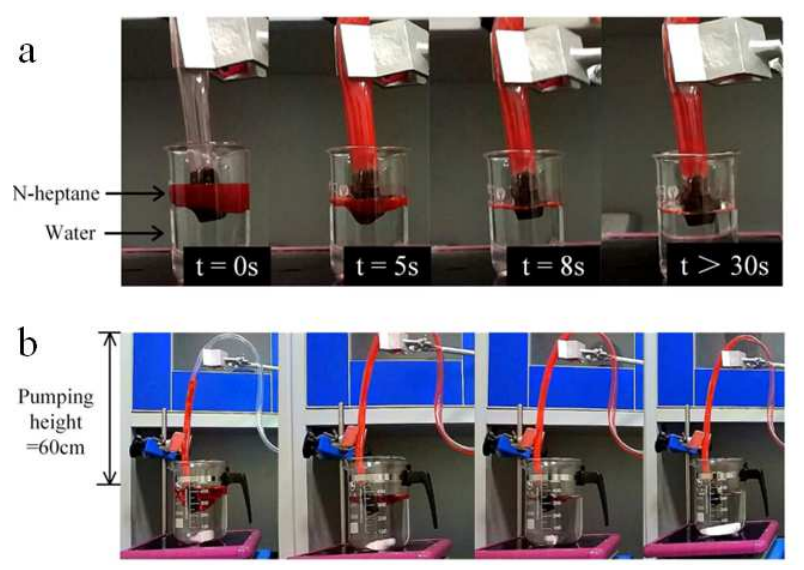

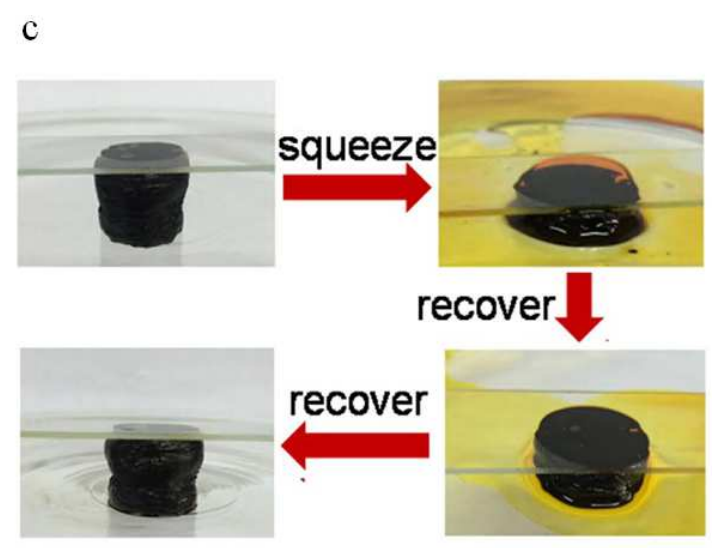

Figure 8. (a) The selective absorption of GA in an oil-water mixture with pump. (b) The continuousremoval of n-heptane using a 120-W pump [12], (c) GA shows excellent repeated absorption of $n$-hexane after multiple times of being compressed above $90 \%$ of its initial height [13].

\subsection{Removal of Lead, Arsenic and Other Heavy Metal Ions from Contaminated Water}

Heavy metal ions, such as lead $\left(\mathrm{Pb}^{2+}\right)$, cadmium $\left(\mathrm{Cd}^{2+}\right)$, chromium $\left(\mathrm{Cr}^{3+}, \mathrm{Cr}^{6+}\right)$, mercury $\left(\mathrm{Hg}^{2+}\right)$, copper $\left(\mathrm{Cu}^{2+}\right)$ and arsenic $\left(\mathrm{As}^{3+}\right)$, have severe risks to environment and human health, and need to be removed from water. Zhuo Han et al. reported the adsorption capacity of $\mathrm{GA}$ for $\mathrm{Pb}^{2+}$ from aqueous solution up to about $80 \mathrm{mg} \mathrm{g}^{-1}$, which could reach as high as $5000 \mathrm{~g} \mathrm{~m}^{-3}$ per unit volume [14]. Mi et al. prepareda GO aerogel with highly oriented porous structure from GO nanosheets by the freeze-drying method [15]. The obtained aerogel can act as a good adsorbent of $\mathrm{Cu}^{2+}$ in aqueous solutions with fast adsorption rate, which attributedto its interconnected pore structure being conducive to the diffusion of $\mathrm{Cu}^{2+}$. Yan Ye et al. reported that the threedimensional $\mathrm{Fe}_{3} \mathrm{O}_{4} / \mathrm{GA}$ is an excellent material for removing arsenic (As) ions from water [16]. This material shows that iron oxide nanoparticles are decorated on graphene with an interconnected network structure and therefore $\mathrm{Fe}_{3} \mathrm{O}_{4} / \mathrm{GA}$ own a capacity of As ions adsorption up to $40.048 \mathrm{mg} / \mathrm{g}$ due to their remarkable 3D structure and existence of magnetic $\mathrm{Fe}_{3} \mathrm{O}_{4}$ nanoparticles for separation.

It is very interesting to note that owing to the excellent adsorption capability of $\mathrm{Pb}^{2+}$ and $\mathrm{As}^{3+}$ ions and other heavy metals ions, GAs can be used to easily and effectively separate these metal ions from water, indicating the potential applications in water treatment.

\subsection{Air and Gas Purification}

Air pollution is currently one of the most serious environmental problems. Gas and air purification represents a major challenge in a time of concerns for growing air pollution based on emission of gases (especially toxic and greenhouse gases) from various industrial sources.

Regarding the greenhouse gases, the subject of carbon dioxide $\left(\mathrm{CO}_{2}\right)$ capture, utilization, and storage has received widespread attention because of the interest in reducing the amount of released $\mathrm{CO}_{2}$ as a greenhousegas. The amount of $\mathrm{CO}_{2}$ present in the atmosphere contributes to $60 \%$ of global warming effects.
Related to this issue, porous carbons play an important role in $\mathrm{CO}_{2}$ adsorption and separation due to their high porosity, excellent stability, wide availability, and tunable surface chemistry. They are mainly classified into the following categories: conventional activated carbons (ACs), renewableresources-derived porous carbons, synthetic polymer-based porous carbons, graphitic porous carbons, CNT/graphenebased porous materials including aerogels and etc. Among them, aspenand $\mathrm{CNT} /$ graphene aerogelsfor $\mathrm{CO}_{2}$ capture are being created at an increasing rate and are highlighted in the last few years.

Related to the quality of indoor and outdoor airenvironment, to overcome the drawbacks of current air cleaners in the market, new materials and methods for air purifying are needed. In this aspect, the combination of adsorption and photocatalysis is definitelya competitive and applicable way of air cleaning. The adsorbents could concentrate the pollutants around $\mathrm{TiO}_{2}$ to facilitate the photocatalytic reaction, while the photocatalytic oxidation serves as regeneration way of the adsorbents. In this aspect, ultralight, high porosity and highly compressible CNT and graphene aerogels are expected to be the best support for $\mathrm{TiO}_{2}$. Based on this idea, Xicheng Xiong et al. have developed porous graphene aerogels added with $\mathrm{TiO}_{2}$ nanoparticles for air cleaner filters [17]. For cleaning air exhaustedfrom other objectives such as solid waste incinerators, vehicles and motorcycles, it is suggested that one can useCNT and graphene aerogels functionalized by catalyst nanomaterials, such as Zirconium Oxide $\left(\mathrm{ZrO}_{2}\right)$, Cerium Oxide $\left(\mathrm{CsO}_{2}\right)$, Rhodium Oxide $\left(\mathrm{RhO}_{2}\right)$ and platinum (Pt). Three-dimensional printing technology is recommended to be used to create graphene aerogels with a highly ordered pore structure and highlytransported gas flow thus more effective air cleaning [18].

\section{Conclusion}

Carbon nanotube and graphene aerogels, the world's latest materials, haveattracted widespread attention due to its excellent mechanical strength, super compressibility offering up to $90 \%$ compressive strain and high surface area, low 
thermal conductivity and stability, and adsorption capability. With their excellent multifunctional properties, they can be promising candidates for several applications.

However, the greatest obstacle to the widespread use of 3D aerogels is cost. The cost of theseaerogels is not inherent in their composition, but it results from the time and energy used for their production. Therefore, other ways may be found to make three-dimensional CNT more efficiently.

\section{Acknowledgements}

The authors acknowledge financial support from the Vietnam National Foundation for Science and Technology Development (NAFOSTED) under grant number 103.992012.35 and from Center for High Technology Development, Vietnam Academy of Science and Technology.

\section{References}

[1] S. S. Kistler, "Coherent Expanded Aerogels and Jellies," Nature, vol. 127, pp. 741-741, 1931.

[2] Aerogel, Wikipedia, the free encyclopedia, https://en.wikipedia.org/wiki/Aerogel.

[3] L. Zuo, Y. Zhang, L. Zhang, Y. E. Miao, W. Fan, and T. Liu, "Polymer/Carbon-Based Hybrid Aerogels: Preparation, Properties and Applications," Materials (Basel), vol. 8, pp. 6806-6848, Oct 092015.

[4] K. Araki and J. W. Halloran, "New Freeze-Casting Technique for Ceramics with Sublimable Vehicles," Journal of the American Ceramic Society, vol. 87, pp. 1859-1863, 2005.

[5] Nguyen Van Hung, Nguyen Ngoc Anh, Pham Van Trinh, Bui Hung Thang, Nguyen Tuan Hong, Phan Hong Khoi, Phan Ngoc Minh, and Phan Ngoc Hong, Fabrication and Characterization of Carbon Nanotubes Aerogel, 8th IWAMSN (2016), Ha Long City, Vietnam, 8th-12th November 2016.

[6] Y. Lin, F. Liu, G. Casano, R. Bhavsar, I. A. Kinloch, and B. Derby, "Pristine Graphene Aerogels by Room-Temperature Freeze Gelation," Adv Mater, vol. 28, pp. 7993-8000, Sep 2016.

[7] Y. Xie, S. Xu, Z. Xu, H. Wu, C. Deng, and X. Wang, "Interface-mediated extremely low thermal conductivity of graphene aerogel," Carbon, vol. 98, pp. 381-390, 2016.
[8] Z. Xu, H. Sun, and C. Gao, "Perspective: Graphene aerogel goes to superelasticity and ultraflyweight," APL Materials, vol. 1, p. 030901, 2013.

[9] H. Sun, Z. Xu, and C. Gao, "Multifunctional, ultra-flyweight, synergistically assembled carbon aerogels," Adv Mater, vol. 25, pp. 2554-60, May 142013.

[10] Graphene aerogel is lighter than air, Extremetech, https://www.extremetech.com/extreme/153063graphene-aerogel-is-seven-times-lighter-than-air-canbalance-on-a-blade-of-grass

[11] Y. Cheng, S. Zhou, P. Hu, G. Zhao, Y. Li, X. Zhang, et al., "Enhanced mechanical, thermal, and electric properties of graphene aerogels via supercritical ethanol drying and hightemperature thermal reduction," Sci Rep, vol. 7, p. 1439, May 032017.

[12] Y. Luo, S. Jiang, Q. Xiao, C. Chen, and B. Li, "Highly reusable and superhydrophobic spongy graphene aerogels for efficient oil/water separation," Sci Rep, vol. 7, p. 7162, Aug 02 2017.

[13] B. Zhang, J. Zhang, X. Sang, C. Liu, T. Luo, L. Peng, et al., "Cellular graphene aerogel combines ultralow weight and high mechanical strength: A highly efficient reactor for catalytic hydrogenation," Sci Rep, vol. 6, p. 25830, May 122016.

[14] Z. Han, Z. Tang, S. Shen, B. Zhao, G. Zheng, and J. Yang, "Strengthening of graphene aerogels with tunable density and high adsorption capacity towards $\mathrm{Pb}^{2+}, " \mathrm{Sci}$ Rep, vol. 4, p. 5025, May 222014.

[15] X. Mi, G. Huang, W. Xie, W. Wang, Y. Liu, and J. Gao, "Preparation of graphene oxide aerogel and its adsorption for $\mathrm{Cu}^{2+}$ ions," Carbon, vol. 50, pp. 4856-4864, 2012.

[16] Y. Ye, D. Yin, B. Wang, and Q. Zhang, "Synthesis of ThreeDimensional $\mathrm{Fe}_{3} \mathrm{O}_{4} /$ Graphene Aerogels for the Removal of Arsenic Ions from Water," Journal of Nanomaterials, vol. 2015, pp. 1-6, 2015.

[17] X. Xiong, N. Ji, C. Song, and Q. Liu, "Preparation Functionalized Graphene Aerogels as Air Cleaner Filter," Procedia Engineering, vol. 121, pp. 957-960, 2015.

[18] Q. Zhang, F. Zhang, S. P. Medarametla, H. Li, C. Zhou, and D. Lin, "3D Printing of Graphene Aerogels," Small, vol. 12, pp. 1702-8, Apr 062016. 